\title{
What Can We Learn from the Organizational Life Cycle Theory? A Conceptualization for the Practice of Workplace Learning
}

\author{
Steven Tam (Corresponding author) \\ Dept. of Management, Fort Hays State University \\ Hays, KS 67601, USA \\ E-mail: stam@fhsu.edu \\ David E. Gray \\ Business School, University of Greenwich \\ Old Royal Naval College, Park Row, London SE10 9LS, UK \\ E-mail: d.e.gray@gre.ac.uk
}

Received: Jan. 12, $2016 \quad$ Accepted: Feb. 23, $2016 \quad$ Published: April 1, 2016

doi:10.5296/jmr.v8i2.9093 URL: http://dx.doi.org/10.5296/jmr.v8i2.9093

\begin{abstract}
In the world of business and management, the practice of workplace learning is deemed important for firms to survive or stay competitive. However, firm characteristics such as business priorities, management styles, and limited internal resources and capabilities are always organizational factors that affect how firms may practice workplace learning. According to organizational life cycle (OLC) theory, during the firm's growth from inception, to high-growth, to maturity, firm characteristics differ and the internal resources and capabilities of the firm develop. The literature has discussed the dynamics of organizational life cycle, but little is known about how it possibly relates to workplace learning. The paper synthesises the OLC literature and draws the characteristics of three common stages for firms (large or small) to conceptualize different patterns of workplace learning practices, promoting a new page of empirical research potential.
\end{abstract}

Keywords: Human resource development, Life-cycle stages, Organizational development, Organizational life cycle, Workplace learning 


\section{Introduction}

Organizations encounter an unpredictable business environment which is constantly pressured by the changing effects of globalization, competition and technological advancement within the context of the knowledge economy (Thoumrungroje \& Tansuhaj, 2007). As such, learning for employees is increasingly regarded as a requirement at work (Sloman \& Webster, 2005) and whether or not they have the capacity to learn also offers to be a source of competitive advantage for a business (Eddy, D'Abate, Tannenbaum, Givens-Skeaton, \& Robinson, 2006). Organizations learn while their employees learn, optimizing staff productivity and firm growth in the long run (Senge, 1993; Chetty \& Campbell-Hunt, 2003).

Organizations, however, grow through a series of stages, a process described by the organizational life cycle(e.g., Greiner, 1972, 1998; Churchill \& Lewis, 1983; Shim, Eastlick, \& Lotz, 2000; Rutherford, Buller, \&McMullen, 2003), or they may experience a non-linear route to advance through states (e.g.,Orser, Hogarth-Scott, \&Riding, 2000; Phelps, Adams, \& Bessant, 2007).In either case, each stage or state has its own characteristics of firm development. The literature has discussed the organizational life cycle (OLC), but little is known about how it relates to workplace learning. The purpose of this paper is to review OLC theory to understand how the concept of growth stages (with different characteristics)would carry specific implications for different workplace learning practices in organizations.

\section{Literature Review of OLC Theory}

The OLC literature has only been in existence for about fifty to sixty years. The whole timeline of the development of OLC theory involving both large and small organizations can be synthesized into four major periods - we propose to name them as primitive, contextual, enhanced, and validated - each of which is discussed below:

\subsection{The Primitive Period (1950’s - 1960's)}

Organizational life cycle theory can probably be traced back to the 1950's in the field of economics, where the concept of firm progression is very much viewed in a biological way, like the one for humans (Haire, 1959; Rostow, 1960). Chandler (1962) and Lippitt and Schmidt (1967) discuss this in greater depth from perspectives around strategic change, patterns, structural move, and evolving managerial concerns in growing organizations. Downs (1967) also adds the effect of firm motivation on organizational growth. These scholars theoretically describe the organizational life cycle as stages of development that firms progress over time. Steinmetz (1969) is considered another pioneer in OLC discussion, who first specifies the context of small and medium enterprises (SMEs), but the logic is similarly about transitional problems, management challenges and survival thresholds across stages. 


\subsection{The Contextual Period (1970's)}

In the 1970's, more appealing stage models appeared that set increasing details into the OLC literature. Scott (1971), based on Lippitt and Schmidt's (1967) work, comprehends more fully the dynamics of strategic actions, corporate structure, efficiency and systematic control in management practices over a three-stage path. From a sort of "overall commander role" stage with few rules and systems, to the next stage of more formalized operations and functional specializations by delegated personnel, until a clearly defined organizational and divisional structure is established in the final stage, all of these managerial changes are meant to enhance and promote further business development in an efficient way.

Greiner $(1972,1998)$ launches an influential conceptual framework, proposing five phases of how organizations grow in terms of size (small to large) and age (young to mature) through the evolutionary periods (prolonged growth at times) and the revolutionary periods (turbulent times of crisis, change, or problems). An evolution will end with an inevitable revolution which must be overcome before moving forward to the next evolution. In the model, the five phases of evolution (revolution) are labeled as: creativity (leadership), direction (autonomy), delegation (control), coordination (red tape), and collaboration (stress). It is possible that not every firm will pass through the five phases, or some firms may stay much longer in a particular phase while some may choose to move forward or even backward.

Torbert (1974) studies the cognitive processes in the minds of entrepreneurs in developing their organizations. Nine logical stages are defined, along which rational decision-making, increased creativity and self-reflection importantly guide the development. These stages are fantasy of the owner, financing and resources allocation, office setup, business launch, productivity, corporate structure/synergy toning, work community, disciplines/culture formulation, and vision.

Lyden (1975) suggests four descriptive stages of organizational growth. During the first stage, any organization will start up in a new business environment with much adaptation and try to develop a niche through learning and innovative practices. Given the success of that survival, the organization becomes aggressive in the second stage in managing internal resources, workflows and corporate structure to accommodate the increased complexity of operations. Policies are gradually formed. Coming to the third stage, business efficiency is the core, and the organization keeps resolving workplace problems and defining clear objectives of what to achieve short-term and long-term in the business. Revenue is the key. Finally, for the fourth stage (as a mature stage), the organization tends to maintain the business stability and spend time focusing on institutionalizing the status quo of systems, networks and practices.

Katz and Kahn (1978) study the works of Chandler (1962) and Scott (1971), and describe three stages of structural changes in growing organizations. The first is the primitive stage, in which individual discretion simply determines how the organization is run and how decisions are made. There is little people coordination, control and benchmarking over work. The second is the stable stage, where consistency of practices is sought among different workers through the development of systems and procedures, and team culture is formed. People work in accordance with a standard or common structure. The final is the elaborative stage, in 
which workers become familiar with the existing structure as reflective users and feel able to enhance it continuously to fit with the changing business environment they face.

Adizes $(1979,1988,1999)$ suggests a ten-stage OLC. While it looks complex, the contribution is that organizational growth is a series of passages that the first nine characterize one or more specific roles (PAEI) within each. P stands for Produce the results; A means Administration; E is Entrepreneurial; and I represents Integration. The ten stages are courtship, infant, go-go, adolescent, prime, maturity, aristocracy, early bureaucracy, bureaucracy, and death. According to Adizes (1979, 1988, 1999), in the courtship stage, E is what it takes. In the infant stage, $\mathrm{P}$ is key to succeed. Similarly, in brief terms, go-go has $\mathrm{P}$ and $\mathrm{E}$; adolescent requires $\mathrm{A}$; prime demands $\mathrm{P}, \mathrm{A}$ and $\mathrm{E}$; maturity needs $\mathrm{P}, \mathrm{A}$ and $\mathrm{I}$; aristocracy has A and I; early bureaucracy plays A and I; bureaucracy focuses on A; and death comes with none of them. As noted, this model conceptually provides some foresight for management team of what functional role(s) should be emphasized during different stages of growth to ensure successful transitions.

\subsection{The Enhanced Period (1980’s)}

During this period, most OLC works aimed to improve the existing models or extend the OLC context into the SME environment. Cameron and Whetten (1981) use 18 software-simulated organizations to explore their developments. This study finds that the individuals' interpretations of organizational effectiveness change across three distinct stages of development, which dominate most decisions made about how to run the organization at that moment. In other words, managerial perceptions matter as the firm grows and how it would grow. Later, Cameron, Kim, and Whetten (1987) first propose a stage of decline to the concept of organizational life cycle, indicating that an organization can fail to remain profitable, stable and effective in business.

Galbraith's (1982) conceptual model of five growth stages is considered the next significant work on SMEs after Steinmetz (1969). Referring to high-technology ventures, the author describes the stages as: proof of principle/prototype, model shop, start-up/volume production, natural growth, and strategic maneuvering. These stages are identified with progressive changes in terms of the factors of task, people, reward, processes, structure, and leadership style in the organization.

Churchill and Lewis (1983) mark another great contribution in understanding SME growth. Based on Greiner's (1972) theoretical work, they empirically develop a specific life cycle for small businesses with five stages: existence, survival, success, take-off, and resource maturity. The success stage can also be subdivided into success-disengagement or success-growth. The authors point out that not all the SMEs choose to grow their businesses further (into the take-off stage via the success-growth path), but in reality, some may prefer to base their business stability indefinitely upon the success-disengagement stage. The model is characterized by noting the existence of different organizational problems and changes across different stages. 
Quinn and Cameron (1983) derive a common four-stage model after extensive review of earlier works in OLC. These stages are the entrepreneurial stage, the collectivity stage, the formalization stage, and the elaboration stage. The authors describe the earlier stages as the periods of business flexibility to the environment, resource acquisition and product/service identification, while the later stages as the periods of systematic, structural and group initiatives to enable an innovative firm that can "live" with changes and problems productively in the long run.

Miller and Friesen $(1983,1984)$ similarly study the previous stage models - including Quinn and Cameron's (1983), but name five common OLC stages in a different way: birth, growth, maturity, revival, and decline. The importance of their empirical work lies in two aspects. First, there are differences between successful and unsuccessful organizations in terms of information processing and decision making. Successful ones tend to acquire more sophisticated context for these strategic actions. Second, despite their five-stage model, the authors realize that not all the organizations will move through the same stages in a linear sequence.

Mintzberg (1984) casts new light onto the OLC concept by discussing power and coalition in growing organizations. The work is not to build another stage model, but tries to understand the leader's/manager's state of power across stages - from the centralized power of the leader to the decentralized power in the form of coalitions among managers.

Smith, Mitchell, and Summer (1985) contribute another critical piece of empirical research into organizational effectiveness by connecting management priorities and life-cycle stages. The authors essentially synthesize different OLC discussions into a generic three-stage model (inception, high-growth, and maturity), and validate it by examining the changes in three management priorities (technical efficiency, organizational coordination, and political support) across these stages.

Scott and Bruce (1987) theorize another five-stage growth model for SMEs, which extends the earlier works of Greiner (1972) and Churchill and Lewis (1983). The five stages are named as: inception, survival, growth, expansion, and maturity. The authors believe that SME growth is not linear and may not follow through all the mentioned stages.

Kazanjian (1988) and Kazanjian and Drazin $(1989,1990)$ pose a four-stage OLC model for technology-based new ventures, which relates their dominant problems to different growth stages. The core idea is that "the organization of a venture will be a function of the dominant problems that define a stage of growth" (Kazanjian \&Drazin, 1990, p. 137); and the rate of growth depends on how fast the problems in a stage are overcome (meaning how well the firm is transformed itself to the next level). The authors empirically conclude four stages as conception and development, commercialization, growth, and stability. Kazanjian (1988) finds that human resources are crucial in all of these stages.

\subsection{The Validated Period (1990's and Beyond)}

From this period onwards, scholars show greater interest in debating the linear pattern of growth stages by offering different views, or they strive to validate earlier OLC models 
through empirical means. Hanks (1990) puts forth a growth model for organizations, which, however, is not stage defined but process focused in the form of a decision tree. The author describes firm advancement as a series of human decisions from business idea generation, company/department formation, product and service development, to resource consolidation. As such, there are multiple entry/exit points in the process that determine if the firm will continue (i.e., grow) or stop (i.e., decline) during the life cycle. Hanks (1990) argues that organizations do not necessarily go through defined growth stages, but they operate actively through managing "changes" from one position to the other without a one-way sequence.

Dodge and Robbins (1992) argue that the context of OLC models defined for large firms may not be appropriate for small businesses as they are facing different sets of internal and external environmental variables that invite a different nature of problem. The authors propose a common growth model of four stages: formation, early growth, late growth, and stability.

Hanks, Watson, Jansen, and Chandler (1993) add another empirical study on SME life cycles, which examines the underlying construct of each stage to understand the structure and context. While the study does not focus on change in organizational problems, it describes the different characteristics of the firm in terms of age, no. of employees, sales, and growth rate across the stages.

Gupta and Chin (1993) support the objective of deriving an empirical OLC. In their work with large firms, based on Smith et al.'s (1985) model, they validate the three distinct stages (inception, high growth, and maturity) and investigate the effect of environmental changes on the firm's strategy making through analysis and innovation.

Dodge, Fullerton, and Robbins (1994) test the mediating factor of market competition on SME problems across growth stages in a sizable study (645 SMEs), and find that competition affects the existence of their problems more than does the progression of OLC. In other words, it raises a question of the direct relationship between organizational problems and different stages of growth, especially in smaller firms. The study attempts to explain that "small business firms are oriented toward survival rather than growth" (Dodge et al., 1994, p. 132), and their short-term business perspective may not fit so well into the evolving concept of OLC.

Hanks and Chandler's (1994) empirical work is regarded as a close addition to the model by Kazanjian (1988) and Kazanjian and Drazin (1989, 1990), although the stage names are slightly altered (conception and development, commercialization, expansion, and consolidation). Using SMEs in high technology industries, Hanks and Chandler (1994) agree with the progressive problems that are faced by the firm across the four different stages. On top of this, they find that task specialization also follows the OLC in such a way that younger firms will have less specialized tasks than older firms in the workplace.

Mitra and Pingali's (1999) study was regarded as the first empirical research going beyond the Western context to explore SME growth. The authors adopt Churchill and Lewis's (1983) growth model and validate it by using small firms in the automobile ancillary sector in India. 
The study recognizes the possibility of divergent paths in SME growth due to different management choices in responding to individual business situations; in other words, owner/managers exert their strategic preferences and can implement alternative paths of growth. Thus, a linear or "one-size-fits-all" model cannot fully reflect the complete picture of SME growth.

Shim et al.(2000) use Churchill and Lewis's (1983) OLC model and examine the growth characteristics of Hispanic-owned small service and retail businesses in the US. The study finds support for the five stages (Existence, Survival, Success, Take-off, and Resource Maturity) of business growth. Shim et al. (2000) also make an observation that is relevant to the dimension of workplace learning - HRM issues increase with firm progression.

Rutherford et al. (2003) conduct a relatively large-scale empirical study of 2,903 SMEs to understand how HRM problems vary over the organizational life cycle. After reviewing the OLC literature, a four-stage growth model is adopted (no growth, low growth, moderate growth, and high growth). Three HRM problems are considered: hiring (operationalized as recruiting), retention (operationalized as compensation), and staff development (operationalized as training). Based on the results, training problems are most prevalent in high-growth firms and least in low-growth firms; compensation problems are most significant in moderate-growth firms and least in high-growth firms; and recruiting problems are most critical in no-growth firms and least in low-growth firms.

Phelps et al. (2007) offer a conceptual framework of the organizational life cycle with a new perspective. They suspect the nature of a linear and predictive stage model, and propose a "state" model governed by tipping points and absorptive capacity of the firm. The authors accept the concept of organizational problems across the OLC; a tipping point is considered a set of related problems that trigger a firm to resolve in order to grow. To continue growth, the firm must successfully overcome the tipping points it encounters, which depends on how knowledgeable the firm is or how well/fast it can acquire the required knowledge (i.e., absorptive capacity) to tackle them. The absorptive capacity of the firm is possibly run on network building and the use of external experts, from which new knowledge is usually constructed.

\section{Discussion}

\subsection{Linear versus Non-Linear Considerations}

Organizational life cycle (OLC) theory is traditionally built on the concept of growth stages that organizations evolve over time in a predictable, linear and consistent manner. As firms move through different stages, they experience different organizational characteristics, problems, structural configurations and strategic/management priorities (e.g., Chandler, 1962; Greiner, 1972, 1998; Smith et al., 1985; Gupta \& Chin, 1993), including SMEs (e.g., Steinmetz, 1969; Churchill \&Lewis, 1983; Shim et al., 2000). Apart from this contextual dimension, another group of authors have their focus on the process/functional changes within an organization across the OLC (e.g., Torbert, 1974; Adizes, 1979, 1988, 1999; Mintzberg, 1984; Hanks, 1990). Most stage models, however, share a common underlying 
logic that organizations have to overcome successive challenges in each stage in order to make growth possible and continuous.

As noted from the literature review of OLC theory, there are a variety of models from three to ten stages. There is no clear evidence about how many stages are most accurate for most firms (Rutherford et al., 2003). While OLC models view business growth as a linear progression, there is also evidence that organizations do not always take this linear path, but instead may take a non-linear route to grow(Orser et al.,2000; Phelps et al., 2007). As a matter of fact, there is no clear understanding of whether firm growth is strictly linear (i.e., stages), strictly nonlinear (i.e., states), or a mix of them.

\subsection{The Common Framework}

Miller and Friesen $(1983,1984)$ study and integrate the previous OLC models from other authors, proposing their five generic growth stages: birth, growth, maturity, revival, and decline, while claiming that not all the organizations will move through the same stages in a linear sequence. Smith et al. (1985) suggest their simpler framework which comes with three standard stages known as inception, high-growth, and maturity. Subsequently, Drazin and Kazanjian (1990) revisit Miller and Friesen's (1983, 1984) five-stage model with additional tests, and conclude that the stages of birth, growth, and maturity are empirically supported. Although it is the case that other authors can name their representative stages differently, the work of Drazin and Kazanjian (1990) lends further evidence to a usable three-stage model, in which the context of each of these stages is simply "natural-to-have" in the life cycle of any organization.

\subsubsection{Birth/Inception}

Birth/Inception is viewed as the beginning stage of the organizational life cycle. Firms at this stage are young, smaller, unstructured, flexible, and informal in managing the business. Their primary objective is to secure necessary resources, build support from business networks and launch the basic operations to ensure survival (Smith et al., 1985). The decision-making channel is simple and direct, with little planning(e.g., Scott, 1971; Mintzberg, 1984). Coordination among staff is also weak since the internal structure of the firm does not really exist to support the teamwork function (e.g., Galbraith, 1982; Quinn \& Cameron, 1983).

\subsubsection{Growth/High-Growth}

A major characteristic of high-growth is the significance of the overall coordination change, where work processes become moderately formal and systematic (Smith et al., 1985). Policies and procedures are taking form, while the whole organizational structure begins to emerge into functional context with task specializations (e.g., Lyden, 1975; Hanks \&Chandler, 1994). It is observed that decision-making remains centralized but is more formalized with the progressive support of analytical tools (e.g., Scott, 1971; Galbraith, 1982; Gupta \&Chin, 1993). During this stage, the firm size increases rapidly, as trained professionals/managers are hired to help share the leadership role in managing the increased complexity of the firm that is dominated with "problems" (e.g., Kazanjian, 1988; Kazanjian \& Drazin, 1989, 1990; Hanks et al., 1993). 


\subsubsection{Maturity}

The maturity stage arrives when the firm is well characterized with a formal organizational structure, supported by established office systems, regulations and work documentation that lead to norms and routines of practices in its workplace (e.g., Scott, 1971; Quinn \&Cameron, 1983; Hanks \&Chandler, 1994). Employees interact often for work, and perform in accordance with common objectives (Katz \&Kahn, 1978). Being more hierarchical, resourceful and bureaucratic in nature, organizations at this stage enjoy an internal operation which is stable, efficient and decentralized (e.g., Greiner, 1972; Churchill \&Lewis, 1983; Scott \&Bruce, 1987). Longer-term planning is adopted, outside talents are strategically recruited, and a team culture is developed (Scott, 1971; Galbraith, 1982).

\section{Conclusions: Conceptualizing the Practice of Workplace Learning}

There is discussion in the literature that the OLC is associated with staff learning and development. For example, the people factor is found significant across growth stages, meaning that employees (and their capabilities) play an important role for organizational growth no matter which stage the firm is in (Kazanjian, 1988). Moy and Luk (2003) echo this with similar results by validating Kazanjian's model for Hong Kong SMEs. Rutherford et al. (2003) also highlight that staff development is very important for high-growth firms, and it needs to be formalized as the firm grows. Although little is known, there is an implied relationship between workplace learning and firm growth.

From the literature review of OLC theory, it casts light on the different characteristics that each growth stage has. These characteristics speak of the differences in firm's resources, structures, business priorities and internal support, which will essentially differentiate how a firm would practice learning in its workplace. In view of workplace learning, it is possible that:

At Birth/Inception - the practice of workplace learning may be individualized and subjective. In other words, no co-workers would give much guidance to what the learner should learn. Employees need to take strong initiatives to seek the learning opportunities they want (and manage their learning).Learning resources are likely to be immature and limited.

At Growth/High-Growth - the practice of workplace learning may shift to more group learning by leveraging work teams and group discussions due to increasing complexity in operations. The overall coordination change in the workplace also intensifies idea sharing and problem solving among people. A learning culture seems to be developed in the fast-paced working environments.

At Maturity - the practice of workplace learning may become more formalized given the established office systems and routines in the workplace. Internal resources are better planned for more structural support, including tools/groupware that promotes knowledge sharing among employees at the organizational level. Learning efforts are strategic as to map with the organizational objectives. People development programs may be part of the strategic plan. 
These ideas, however, are still conceptual. It is intended to empirically test them by selecting a sample of organizations at the birth/inception, growth/high-growth and maturity stages, and investigating the types of learning that are taking place.

\section{References}

Adizes, I. (1979). Organizational passages - Diagnosing and treating lifecycle problems of organizations. Organizational Dynamics, 3-25. http://dx.doi.org/10.1016/0090-2616(79)90001-9

Adizes, I. (1988). Corporate lifecycles: How and why corporations grow and die and what to do about it. Englewood Cliffs, NJ: Prentice Hall.

Adizes, I. (1999). Managing corporate lifecycles. Paramus, NJ: Prentice Hall.

Cameron, K. S., Kim, M. U., \&Whetten, D. A. (1987). Organizational effects of decline and turbulence. Administrative Science Quarterly, 32(2), 222-240. http://dx.doi.org/10.2307/2393127

Cameron, K. S., \&Whetten, D. A. (1981). Perceptions of organizational effectivesness over organizational life cycles. Administrative Science Quarterly, 26(4), 525-544. http://dx.doi.org/10.2307/2392338

Chandler, A. D. (1962). Strategy and structure. Cambridge, MA: MIT Press.

Chetty, S., \&Campbell-Hunt, C. (2003). Paths to internationalisation among small- to medium-sized firms: A global versus regional Approach. European Journal of Marketing, 37(5/6), 796-820. http://dx.doi.org/10.1108/03090560310465152

Churchill, N. C., \&Lewis, V. L. (1983). The five stages of small business growth. Harvard Business Review, 61(3), 30-50.

Dodge, H. R., \&Robbins, J. E. (1992). An empirical investigation of the organizational life-cycle model for small business development and survival. Journal of Small Business Development, 30(Jan), 27-37.

Dodge, H. R., Fullerton, S., \&Robbins, J. E. (1994). The stage of the organizational life-cycle and competition as mediators of problem perception for small businesses. Strategic Management Journal, 15, 121-134. http://dx.doi.org/10.1002/smj.4250150204

Downs, A. (1967). The life cycle of bureaus. In A. Downs (Ed.), Inside bureaucracy(pp. 296-309). San Francisco: Little, Brown and Company.

Eddy, E. R., D’Abate, C. P., Tannenbaum, S. I., Givens-Skeaton, S., \&Robinson, G. (2006). Key characteristics of effective and ineffective developmental interactions. Human Resource Development Quarterly, 17(1), 59-84. http://dx.doi.org/10.1002/hrdq.1161

Galbraith, J. (1982). The stages of growth. Journal of Business Strategy, 3(1), 70-79. http://dx.doi.org/10.1108/eb038958

Greiner, L. E. (1972). Evolution and revolution as organizations grow. Harvard Business 
Review, 50(4), 37-46.

Greiner, L. E. (1998). Evolution and revolution as organizations grow (updated). Harvard Business Review, 76(3),55-68.

Gupta, Y. P., \&Chin, D. C. W. (1993). Strategy making and environment: An organizational life-cycle $\quad$ perspective. $\quad$ Technovation, $27-44$. http://dx.doi.org/10.1016/0166-4972(93)90012-K

Haire, M. (1959). Biological models and empirical history of the growth of organizations. In M. Haire (Ed.), Modern organizational theory(pp. 272-306). New York: John Wiley \& Sons.

Hanks, S. H. (1990). The organization life cycle: Integrating content and process. Journal of Small Business Strategy, 1(1), 1-13.

Hanks, S. H., \&Chandler, G. N. (1994). Patterns of functional specialization in emerging high tech. Journal of Small Business Management, 32, 23-36.

Hanks, S. H., Watson, C. J., Jansen, E., \&Chandler, G. N. (1993). Tightening the life-cycle construct: A taxonomic study of growth stage configurations in high-technology organizations. Entrepreneurship: Theory \& Practice, 18, 5-29.

Katz, D., \& Kahn, R. L. (1978). The social psychology of organizations ( $2^{\text {nd }}$ ed). New York: John Wiley.

Kazanjian, R. K. (1988). Relation of dominant problems to stages of growth in technology-based new ventures. Academy of Management Journal, 31(2), 257-279. http://dx.doi.org/10.2307/256548

Kazanjian, R. K., \& Drazin, R. (1989). An empirical test of a stage of growth progression model. Management Science, 35, 1489-1503. http://dx.doi.org/10.1287/mnsc.35.12.1489

Kazanjian, R. K., \& Drazin, R. (1990). A stage-contingent model of design and growth for technology based new ventures. Journal of Business Venturing, 5(3), 137-150. http://dx.doi.org/10.1016/0883-9026(90)90028-R

Lippitt, G. L., \& Schmidt, W. H. (1967). Crises in a developing organization. Harvard Business Review, 45, 102-112.

Lyden, F. J. (1975). Using Parson's functional analysis in the study of public organizations. Administrative Science Quarterly, 20(1), 59-70. http://dx.doi.org/10.2307/2392123

Miller, D., \&Friesen, P. H. (1983). Successful and unsuccessful phases of the corporate life cycle. Organization Studies, 4(4), 339-356. http://dx.doi.org/10.1177/017084068300400403

Miller, D., \&Friesen, P. H. (1984). A longitudinal study of the corporate life cycle. Management Science, 30,1161-1183. http://dx.doi.org/10.1287/mnsc.30.10.1161

Mintzberg, H. (1984). Power and organization life-cycles. Academy of Management Review, 9, 207-224.

Mitra, R., \&Pingali, V. (1999). Analysis of growth stages in small firms: A case study of automobile ancillaries in India. Journal of Small Business Management, 37(3), 62-75. 
Moy, J. W., \&Luk, W. M. (2003). The life-cycle model as a framework for understanding barriers to SME growth in Hong Kong. Asia Pacific Business Review, 10(2), 199-220. http://dx.doi.org/10.1080/13602380410001677218

Orser, B., Hogarth-Scott, S., \&Riding, A. L. (2000). Performance, firm size, and management problem solving. Journal of Small Business Management, 38(4), 42-59.

Phelps, R., Adams, R., \& Bessant, J. (2007). Life cycles of growing organizations: A review with implications for knowledge and learning. International Journal of Management Reviews, 9(1), 1-30. http://dx.doi.org/10.1111/j.1468-2370.2007.00200.x

Quinn, R. E., \&Cameron, K. (1983). Organizational life cycles and shifting criteria of effectiveness: Some preliminary evidence. Management Science, 29, 33-51. http://dx.doi.org/10.1287/mnsc.29.1.33

Rostow, W. W. (1960). The stages of economic growth. Cambridge: Cambridge University Press.

Rutherford, M. W., Buller, P. F., \&McMullen, R. (2003). Human resources management problems over the life cycle of small to medium-sized firms. Human Resource Management, 42(4), 321-335. http://dx.doi.org/10.1002/hrm.10093

Scott, B. R. (1971). Stages of corporate development (Part I). Case Note No. 9-371-294. Boston: Harvard Business School Case Services.

Scott, M., \&Bruce, R. (1987). Five stages of growth in small business. Long Range Planning, 20, 45-52. http://dx.doi.org/10.1016/0024-6301(87)90071-9

Senge, P. M. (1993). Transforming the practice of management. Human Resource Development Quarterly, 4(1), 5-32. http://dx.doi.org/10.1002/hrdq.3920040103

Shim, S., Eastlick, M. A., \&Lotz, S. (2000). Examination of US Hispanic-owned small retail and service businesses: An organizational life-cycle approach. Journal of Retailing and Consumer Services, 7(1),19-32. http://dx.doi.org/10.1016/S0969-6989(99)00015-6

Sloman, M., \&Webster, L. (2005). Training to learning. $T+D, 59(9), 58-62$.

Smith, K. G., Mitchell, T. R., \&Summer, C. E. (1985). Top level management priorities in different stages of the organizational life cycle. Academy of Management Journal, 28(4), 799-820. http://dx.doi.org/10.2307/256238

Steinmetz, L. L. (1969). Critical stages of small business growth: When they occur and how to survive them. Business Horizons, 12, 29-36. http://dx.doi.org/10.1016/0007-6813(69)90107-4

Thoumrungroje, A., \&Tansuhaj, P. (2007). Globalization effects and firm performance. Journal of International Business Research, 6(2), 43-58.

Torbert, W. R. (1974). Pre-bureaucratic and post-bureaucratic stages of organization development. Interpersonal Development, 5(1), 1-25. 


\section{Copyright Disclaimer}

2016, Vol. 8, No. 2

Copyright for this article is retained by the author(s), with first publication rights granted to the journal.

This is an open-access article distributed under the terms and conditions of the Creative Commons Attribution license (http://creativecommons.org/licenses/by/3.0/). 